\title{
Out-of-hospital cardiac arrest survivors need both cardiological and neurological rehabilitation!
}

Citation for published version (APA):

Boyce, L. W., Goossens, P. H., Moulaert, V. R., Pound, G., \& van Heugten, C. M. (2019). Out-of-hospital cardiac arrest survivors need both cardiological and neurological rehabilitation! Current Opinion in Critical Care, 25(3), 240-243. https://doi.org/10.1097/MCC.0000000000000609

Document status and date:

Published: 01/06/2019

DOI:

10.1097/MCC.0000000000000609

Document Version:

Publisher's PDF, also known as Version of record

Document license:

Taverne

Please check the document version of this publication:

- A submitted manuscript is the version of the article upon submission and before peer-review. There can be important differences between the submitted version and the official published version of record.

People interested in the research are advised to contact the author for the final version of the publication, or visit the DOI to the publisher's website.

- The final author version and the galley proof are versions of the publication after peer review.

- The final published version features the final layout of the paper including the volume, issue and page numbers.

Link to publication

\footnotetext{
General rights rights.

- You may freely distribute the URL identifying the publication in the public portal. please follow below link for the End User Agreement:

www.umlib.nl/taverne-license

Take down policy

If you believe that this document breaches copyright please contact us at:

repository@maastrichtuniversity.nl

providing details and we will investigate your claim.
}

Copyright and moral rights for the publications made accessible in the public portal are retained by the authors and/or other copyright owners and it is a condition of accessing publications that users recognise and abide by the legal requirements associated with these

- Users may download and print one copy of any publication from the public portal for the purpose of private study or research.

- You may not further distribute the material or use it for any profit-making activity or commercial gain

If the publication is distributed under the terms of Article $25 \mathrm{fa}$ of the Dutch Copyright Act, indicated by the "Taverne" license above, 


\title{
Out-of-hospital cardiac arrest survivors need both cardiological and neurological rehabilitation!
}

\author{
Liesbeth W. Boyce ${ }^{\mathrm{a}, \mathrm{b}}$, Paulien H. Goossens ${ }^{\mathrm{c}}$, Véronique R. Moulaert ${ }^{\mathrm{d}}$, \\ Gemma Pound ${ }^{\mathrm{e}}$, and Caroline M. van Heugten ${ }^{\mathrm{f}, \mathrm{g}, \mathrm{h}}$
}

\begin{abstract}
Purpose of review
Most survivors of out-of-hospital cardiac arrest (OHCA) suffer from cardiologic symptoms and approximately half of them experience cognitive problems because of hypoxic brain damage. Symptoms of anxiety and depression are also common. This review aims to give an overview of recent literature on rehabilitation treatment aiming at improvement of quality of life after OHCA.
\end{abstract}

\section{Recent findings}

Existing cognitive screening tools are now validated for OHCA survivors. OHCA patients with cognitive deficits may have lower exercise capacity. Cardiac rehabilitation seems to be well tolerated for OHCA survivors, with outcomes comparable to myocardial infarction patients. Many caregivers suffer from posttraumatic stress disorder and emotional stress. Interventions for them are available. Implementation of integrated programs covering both cognitive and cardiac rehabilitation is hampered by lack of knowledge and organizational barriers.

\begin{abstract}
Summary
OHCA survivors should be routinely screened for cognitive and emotional problems. When patients with mild cognitive deficits participate in cardiac rehabilitation, their program should be adjusted to their cognitive abilities. For patients with severe cognitive or emotional problems, individualized rehabilitation seems favorable. Integrated rehabilitation treatment between cardiac and cognitive rehabilitation departments is recommended. Attention should be paid to the burden of caregivers.
\end{abstract}

\section{Keywords}

cardiac rehabilitation, caregivers, cognitive rehabilitation, resuscitation, screening

\section{INTRODUCTION}

With the improvements made in the chain of survival, survival rates after out-of-hospital cardiac arrest (OHCA) have increased and are expected to increase even more, for example, by creating citizen responder networks [1-3]. Survivors of OHCA suffer from sequelae of physical, cognitive, and emotional consequences. Approximately half of them experience cognitive problems and even more survivors experience symptoms of anxiety, depression, or posttraumatic stress [4-7]. These impairments have serious impact on daily functioning, societal participation, and quality of life $\left[8^{-"}, 9,10\right]$. Therefore, it is crucial not only to focus on survival but also pay attention to the long-term outcome of survivors.

'Individuals surviving OHCA are at high risk of long-term cognitive impairment and mental health issues with a negative impact on participation and quality of life.'

\section{CARDIAC REHABILITATION AFTER OUT- OF-HOSPITAL CARDIAC ARREST}

In most cases, OHCA is of cardiogenic cause and therefore patients should follow cardiac rehabilitation [11]. Cardiac rehabilitation programs traditionally focus on education aimed at a healthy lifestyle and improvement of exercise capacity with the goal of returning to 'normal' life [12]. One study described a negative correlation between cognitive impairments

\footnotetext{
aLeiden University Medical Center, ${ }^{\mathrm{b}}$ Basalt Rehabilitation, Leiden, ${ }^{\mathrm{c}}$ Merem Rehabilitation, Lelystad, ${ }^{\mathrm{d} C e n t r e}$ for Rehabilitation, University of Groningen, University Medical Centre Groningen, Groningen, The Netherlands, ${ }^{e}$ Monash University, Melbourne, Australia, ${ }^{\mathrm{f}}$ Limburg Brain Injury Center, ${ }^{9}$ School for Mental Health and Neuroscience and hDepartment of Neuropsychology and Psychopharmacology, Maastricht University, Maastricht, The Netherlands
}

Correspondence to Liesbeth W. Boyce, Basalt Rehabilitation, Leiden, The Netherlands. E-mail: I.boyce@basaltrevalidatie.nl

Curr Opin Crit Care 2019, 25:240-243

DOI:10.1097/MCC.0000000000000609 


\section{KEY POINTS}

- All OHCA survivors need to be screened for cognitive and emotional problems.

- Rehabilitation program for OHCA survivors needs to be adjusted to cognitive abilities.

- Partner/Caregiver needs attention because of

$\circ$ anxiety, depression, and posttraumatic stress disorder

o unmet educational needs.

- Cognitive deficits after OHCA may result in lower exercise capacity.

- Cooperation of cognitive and cardiac rehabilitation is possible if mutual knowledge is sufficient and organizational factors are fulfilled.

and exercise capacity after OHCA [13]. Unfortunately, there is little research investigating cardiac rehabilitation specifically for the OHCA population. But cardiac rehabilitation for OHCA survivors seems to be well tolerated and the outcomes comparable to cardiac rehabilitation after myocardial infarction [14].

For cardiac patients with mild-to-moderate physical deficits without additional problems, online or telephone cardiac rehabilitation seems to be as effective as and more cost-efficient than center-based programs [15]. However, OHCA survivors specifically have experienced a tumultuous and life-changing event. Fear, anxiety, loss of memory, and difficulty adjusting to a new reality, both in relationships with other people, as well as in the relationship with their own body, are part of their experiences. The presence of anxiety and depression do not only negatively influence quality of life but also known to increase the risk of new cardiac events and mortality [16]. OHCA survivors may need a more holistic pathway, focusing on both physiological and psychological function [17"'].

Attention is also needed for spouses and caregivers that do not feel well supported in cardiac programs $\left[17^{-"}\right]$. They often show symptoms of anxiety, depression, and posttraumatic stress because of the witnessed arrest, the bystander cardiopulmonary resuscitation, and the long intensive care unit stay [18]. Cardiac patients and spouses have unmet education needs following an acute cardiac event and information increases control and decreases negative emotions associated with diagnosis [19"]. Cardio pulmonary resuscitation (CPR) training for spouses may also be useful to diminish fear [19"].
'After an OHCA, patients and spouses need psychosocial and emotional support as part of cardiac rehabilitation.'

\section{SCREENING}

When assessing outcome of cardiac arrest, studies have traditionally focused on survival rates and relatively short-term clinician-based assessments. The Utstein-style guidelines recommend using the 5-point Cerebral Performance Category (CPC) scale to assess neurological outcome after cardiac arrest [20]. Patients with CPC scores of 3 or higher are commonly regarded as having 'poor' outcome. Patients with CPC 1, able to return to normal activities, and CPC 2, able to live independently, are regarded as good outcomes. Studies using the CPC have suggested that the majority of cardiac arrest survivors have a good neurological outcome [21]. However, half of the patients with a CPC of 1 or 2 experience problems in cognition or emotional wellbeing that were not identified using the CPC [22"]. On neuropsychological tests, deficits of attention, declarative memory, executive function, visuospatial abilities, and verbal fluency are found [7]. In daily practice, it is not possible to administer neuropsychological tests to all survivors. The Montreal Cognitive Assessment (MoCA) - a cognitive screening instrument - seems to have good correlation to the Computer Assessment of mild cognitive impairment in patients surviving cardiac arrest [23"]. The MoCA can be administered by regular hospital staff and takes approximately $10 \mathrm{~min}$. When it is not possible to administer an objective screening, a questionnaire asking the caregiver may provide better information than asking the patient himself [24]. To screen for emotional problems, the Hospital Anxiety and Depression Scale (HADS), that covers both anxiety and depressive symptoms, seems to be a useful questionnaire $\left[22^{\prime \prime}\right]$.

'Screening for cognitive and emotional impairments after OHCA is highly recommended. The MoCA seems to be a sensitive cognitive screening tool for this purpose. The HADS is recommended to screen for emotional problems.'

\section{COGNITIVE REHABILITATION AFTER OUT- OF-HOSPITAL CARDIAC ARREST}

Cognitive rehabilitation focuses on the consequences of the cognitive impairments on the 'activity and participation' level on the basis of the International 
Health Condition

(disorder or disease)

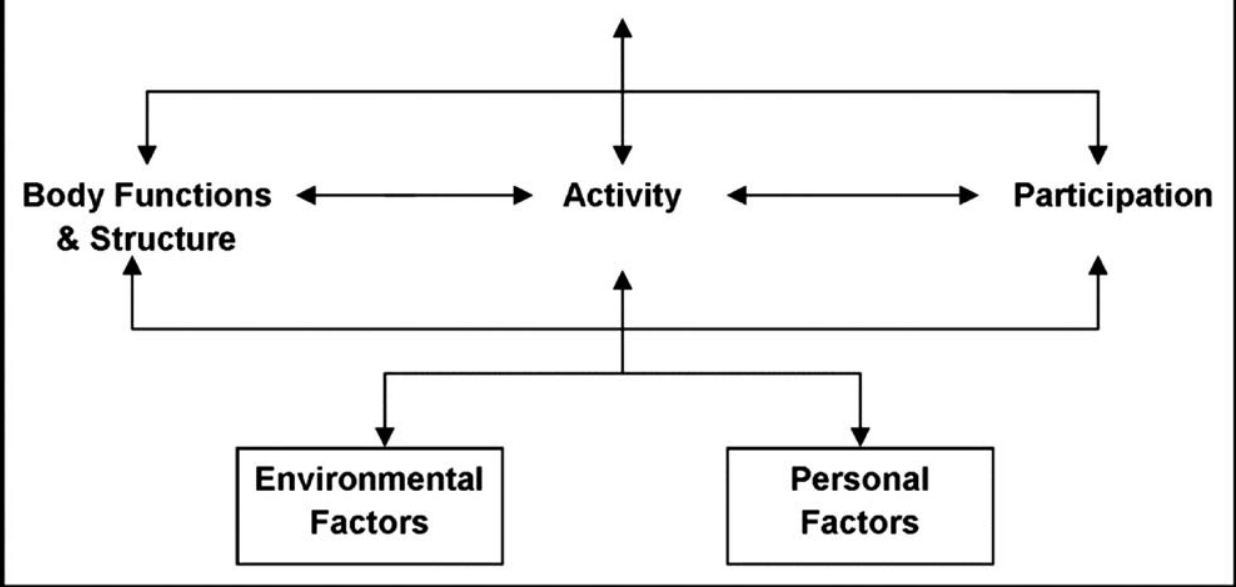

FIGURE 1. The International Classification of Functioning, Disability, and Health model.

Classification of Functioning, Disability, and Health of the World Health Organization (Fig. 1) [25]. The rehabilitation physician and his team determine the health consequences of the OHCA across all domains of functioning and take the desired level of activity and participation of the patient into account. This leads to a treatment plan that teaches the patient and their families compensatory techniques to recognize, live with, manage, bypass, reduce, or come to terms with cognitive deficits [26].

Most rehabilitation teams that are specialized in cognitive rehabilitation, however, have limited knowledge of cardiac rehabilitation and vice versa. Cooperation between cardiological and neurological rehabilitation teams is needed to provide patients a holistic treatment program that covers all sequelae of their cardiac arrest [17"'].

'Cooperation between cardiological and neurological rehabilitation teams is needed in case of cognitive consequences.'

\section{INTEGRATED REHABILITATION CARE PATH}

In the Netherlands, both cardiac and cognitive rehabilitation teams are available throughout the country, covered by insurance companies and thus easily accessible for patients. A large majority (89\%) of healthcare providers involved in care for OHCA patients support the idea of a combined cardiac and cognitive program after cardiac arrest. However, this same survey showed that cognitive and emotional screening tools are not taken out routinely and not all patients are offered cardiac rehabilitation [27].

There are few articles exploring interventions focused on improving quality of life for survivors of $\mathrm{CA}$. Hence, the effectiveness of these programs is not well known. A concise intervention that consists of screening for cognitive and emotional problems and provision of information has been developed and seems clinically feasible and cost-effective [28].

It seems sensible to refer patients with more severe cognitive problems to an individualized cognitive rehabilitation program with involvement of a cardiologist for exercise training advice. Patients with mild-to-moderate cognitive problems will probably benefit from a cardiac rehabilitation program that takes into account cognitive problems. Smaller training groups, less distracting stimuli, for example, loud music, and avoidance of dual tasks may be necessary. This implies that cardiac training personnel should at least have some knowledge of cognitive training principles. During the cardiac rehabilitation, a meeting with a cognitive rehabilitation specialist or psychologist can be scheduled to decide whether a cognitive rehabilitation trajectory is needed. A program covering these aspects has been developed in the Netherlands [29].

\section{CONCLUSION}

All OHCA survivors should be routinely screened for cognitive and emotional problems. The objective MoCA test seems well suited for this purpose. When it is not possible to administer the MoCA, a 
questionnaire for family or caregivers can be considered. To screen for emotional problems, the HADS is a useful questionnaire. Patients with cognitive deficits after OHCA may have a lower exercise capacity. Their rehabilitation program should be adjusted to their cognitive abilities. Emotional support should be offered to the patients and their caregivers. For patients with severe cognitive deficits, individualized cognitive rehabilitation is needed that focuses on compensation strategies to reach maximal participation. Also in patients with cognitive deficits, expertise in cardiology is needed to design a proper training schedule. Therefore, cooperation is needed between cardiac and cognitive rehabilitation specialties.

\section{Acknowledgements}

None.

\section{Financial support and sponsorship}

None.

\section{Conflicts of interest}

There are no conflicts of interest.

\section{REFERENCES AND RECOMMENDED READING}

Papers of particular interest, published within the annual period of review, have been highlighted as:

- of special interest

- of outstanding interest

1. Buick JE, Drennan IR, Scales DC, et al. Improving temporal trends in survival and neurological outcomes after out-of-hospital cardiac arrest. Circ Cardiovasc Qual Outcomes 2018; 11:e003561.

2. Pijls RW, Nelemans PJ, Rahel BM, Gorgels AP. Factors modifying performance of a novel citizen text message alert system in improving survival of outof-hospital cardiac arrest. Eur Heart J Acute Cardiovasc Care 2018; 7: 397-404.

3. McCoy AM. Ten steps to improve cardiac arrest survival in your community. Cardiol Clin 2018; 36:335-342. (Review).

4. Stamenova V, Nicola R, Aharon-Peretz J, et al. Long-term effects of brief hypoxia due to cardiac arrest: hippocampal reductions and memory deficits. Resuscitation 2018; 126:65-71.

5. Sekhon MS, Ainslie PN, Griesdale DE. Clinical pathophysiology of hypoxic ischemic brain injury after cardiac arrest: a 'two-hit' model. Crit Care 2017; 21:90.

6. Caro-Codón J, Rey JR, Lopez-de-Sa E, et al. Long-term neurological outcomes in out-of-hospital cardiac arrest patients treated with targeted-temperature management. Resuscitation 2018; 133:33-39.

7. Naber D, Bullinger M. Psychiatric sequelae of cardiac arrest. Dialog Clin Neurosci 2018; 20:73-77.

8. Presciutti A, Sobczak E, Sumner JA, et al. The impact of psychological

- distress on long-term recovery perceptions in survivors of cardiac arrest. Crit Care 2018; 18:227-233.

This study shows that depressive symptoms are associated with cardiac arrest survivors' negative recovery perceptions postdischarge.
9. Green CR, Botha JA, Tiruvoipati R. Cognitive function, quality of life and mental health in survivors of our-of-hospital cardiac arrest: a review. Anaesth Intensive Care 2015; 43:568-576.

10. Verberne D, Moulaert V, Verbunt J, van Heugten C. Factors predicting quality of life and societal participation after survival of a cardiac arrest: a prognostic longitudinal cohort study. Resuscitation 2018; 123:51-57.

11. Boyce LW, Vliet Vlieland TP, Bosch J, et al. High survival rate of $43 \%$ in out-ofhospital cardiac arrest patients in an optimised chain of survival. Neth Heart J 2015; 23:20-25.

12. González-Salvado V, Rodríguez-Núñez A, González-Juanatey JR. From prevention to rehabilitation: toward a comprehensive approach to tackling cardiac arrest. Rev Esp Cardiol 2019; 72:3-6.

13. Boyce LW, Reinders CC, Volker G, et al. Out-of-hospital cardiac arrest survivors with cognitive impairments have lower exercise capacity. Resuscitation 2017; 115:90-95.

14. Kim $\mathrm{C}$, Jung $\mathrm{H}$, Choi $\mathrm{HE}$, Kang $\mathrm{SH}$. Cardiac rehabilitation after acute myocardial infarction resuscitated from cardiac arrest. Ann Rehabil Med 2014; 38:799-804.

15. Maddison R, Rawstorn JC, Stewart RA, et al. Effects and costs of real-time cardiac telerehabilitation: randomised controlled noninferiority trial. Heart 2019; 105:122-129.

16. Sommaruga $M$, Angelino $E$, Della Porta $P$, et al. Best practice in psychological activities in cardiovascular prevention and rehabilitation: position paper. Monaldi Arch Chest Dis 2018; 88:966.

17. Haydon $G$, van der Riet $P$, Inder $K$. A systematic review and meta-synthesis of

1. the qualitative literature exploring the experiences and quality of life of survivors of a cardiac arrest. Eur J Cardiovasc Nurs 2017; 16:475-483.

This systematic review provides insights into the experiences of survivors' quality of life (QOL) after CPR and valuable recommendations how to improve QOL.

18. Van't Wout Hofland J, Moulaert V, van Heugten C, Verbunt J. Long-term quality of life of caregivers of cardiac arrest survivors and the impact of witnessing a cardiac event of a close relative. Resuscitation 2018; 128: $198-203$.

19. Cartledge S, Feldman S, Bray JE, et al. Understanding patients and spouses

- experiences of patient education following a cardiac event and eliciting attitudes and preferences towards incorporating cardiopulmonary resuscitation training: a qualitative study. J Adv Nurs 2018; 74:1157-1169.

The qualitative study shows that cardiac patients and spouses have unmet education needs following an acute cardiac event and advise how to influence this gap in the care system.

20. Jacobs I, Nadkarni V, Bahr J, et al. Cardiac arrest and cardiopulmonary resuscitation outcome reports: update and simplification of the Utstein templates for resuscitation registries. Resuscitation 2004; 63:233-249.

21. Tiainena M, Vaahersalob J, Skrifvarsb MB, et al. Surviving out-of-hospital cardiac arrest: the neurological and functional outcome and health-related quality of life one year later. Resuscitation 2018; 129:19-23.

22. Viktorisson $A$, Sunnerhagen $K S$, Pöder $U$, et al. Well being among survivors of

- out-of-hospital cardiac arrest: a cross-sectional retrospective study in Sweden. BMJ Open 2018; 6:8.

The retrospective study shows that OHCA survivors with good neurological outcome experience a reduced sense of wellbeing.

23. Koller AC, Rittenberger JC, Repine MJ, et al. Comparison of three cognitive exams in cardiac arrest survivors. Resuscitation 2017; 116:98-104.

The clinical article shows that the $\mathrm{CAMCl}$ and MoCA are useful to assess cognitive problems in cardiac arrest survivors.

24. Blennow Nordström E, Lilja G, Arestedt K, et al. Validity of the IQCODE-CA: an informant questionnaire on cognitive decline modified for a cardiac arrest population. Resuscitation 2017; 118:8-14.

25. WHO. International classification of functioning, disability and health. Geneva: ICF; 2001.

26. Wilson BA, Carney $\mathrm{N}$, Chesnut RM, et al. Cognitive rehabilitation: how it is and how it might be: Effect of cognitive rehabilitation on outcomes for persons with traumatic brain injury: a systematic review. J Int Neuropsychol Soc 1997; 3:487-496.

27. Boyce LW, Goossens PH, Volker G, et al. Attention needed for cognitive problems in patients after out-of-hospital cardiac arrest: an inventory about daily rehabilitation care. Neth Heart J 2018; 26:493-499.

28. Moulaert VR, Verbunt JA, Bakx WG, et al. 'Stand still ..., and move on', a new early intervention service for cardiac arrest survivors and their caregivers: rationale and description of the intervention. Clin Rehabil 2011; 25:867-879.

29. Boyce LW, Goossens PH. Rehabilitation after cardiac arrest: integration of neurologic and cardiac rehabilitation. Semin Neurol 2017; 37:94-102. 